\title{
Interfaces e letramentos digitais na formação continuada de professores
}

\author{
Claudia Vivien Carvalho de Oliveira Soares \\ Universidade Estadual do Sudoeste da Bahia (UESB) \\ Vitória da Conquista, Brasil \\ claudiavivien@uesb.edu.br
}

\begin{abstract}
Resumo - O presente texto objetiva refletir sobre a formação continuada de professores para o uso de tecnologias digitais, bem como discutir as possibilidades de práticas de letramento digital no contexto escolar, de forma que possam efetivamente contribuir nos processos de ensino e de aprendizagem. Este trabalho vincula-se aos estudos desenvolvidos pelo Grupo de Pesquisa Linguagens, Tecnologias e Educação-GPLite/CNPq/UESB e nas pesquisas desenvolvidas pela Linguística Aplicada Crítica (LAC), na perspectiva de uma proposta que seja responsiva à vida social. De cunho qualitativo e intervencionista, a pesquisa foi desenvolvida em parceria com uma escola pública estadual localizada no município de Vitória da Conquista, na Bahia, com 06 professores em efetivo exercício. Os resultados nos mostram que os processos de formação continuada no cotidiano do professor propiciam produções e reflexões colaborativas e compartilhadas e que sua participação em práticas de letramento digital requer um movimento de construção de possibilidades que levem em consideração a interconexão entre conteúdo, tecnologia e pedagogia.
\end{abstract}

Palavras chave: Letramentos digitais, Formação Continuada, Tecnologias Digitais.

\section{INTRODUÇÃO}

A utilização de tecnologias digitais em contextos educacionais implica em propostas de trabalho, que, para se efetivarem, necessitam do reconhecimento de que por estarmos sempre em interação com o mundo, nosso conhecimento é construído continuamente e colaborativamente, considerando nossa natureza social, histórica e cultural. Temos, então, o fundamento de que somos seres inacabados e em constante processo de aprendizagem. A nossa experiência como seres humanos nos ensina, a cada dia, novos caminhos [1], novos saberes, novos letramentos e novas práticas.

Ao tratarmos de letramentos em contexto digital, levamos em consideração as constantes mudanças que permeiam o nosso viver em sociedade, como também o nosso fazer como sujeitos ativos que têm o potencial de gerar a transformação e, ao mesmo tempo, permitir-se serem por ela transformados em uma constante relação dialógica. Nesse sentido, compreendemos que se a inovação tecnológica é permanente as práticas letradas também obedecem a um movimento crescente de significações. Constituímo-nos na coletividade e nos transformamos em uma rede humana que se comunica sem limitações de tempos e de espaços.

O desenvolvimento gerado pela Web 2.0 nos proporciona novas formas de nos relacionarmos com a informação e com o conhecimento no momento em que nos oportuniza um rompimento com o consumo e a transmissão, dando lugar a (re)criação e ao compartilhamento de forma interativa e colaborativa. Participamos, então, de um processo em que a autoria nos convida a re(pensar) valores e práticas condizentes com a sociedade contemporânea. Nesse sentido, entendemos a importância de que as práticas educativas estejam em consonância com a realidade social mais abrangente. A cada dia, surgem dispositivos e aplicativos com interfaces diversas e, consequentemente, diferentes formas de uso, demandando, portanto, novos letramentos, novas práticas. Somando-se a isso, "a cada minuto que passa, novas pessoas passam a acessar a Internet, novos computadores são interconectados, novas informações são injetadas na rede" [2] trazendo dinamismo em relação às formas de conexão, comunicação e interação. Consideramos que a ação refletida pode nos trazer possibilidades concretas de uso que dependem da realidade vivenciada por cada grupo em seus espaços de ensino e aprendizagem. Ao adentrarmos o ciberespaço percebemos que são inúmeras as possibilidades pedagógicas trazidas pelas novas mídias e, junto com essas possibilidades, o desafio de pensar na união entre tecnologia, metodologia e conteúdo. O que nos move em direção ao desenvolvimento de pesquisas que visem à formação continuada de professores, considerando, no entanto, que a simples presença de tecnologias novas em sala de aula não garante processos inovadores. Evidenciamos que apesar do nosso entendimento em torno da importância das tecnologias que, há algum tempo, fazem parte do cotidiano das escolas (giz, quadro, livros, etc) há neste trabalho uma preocupação com a utilização das interfaces digitais disponíveis a partir do advento da $\mathrm{Web}$ 2.0, por favorecem a produção de conteúdo digital de forma interativa, colaborativa e aberta, possibilitando ao professor novas perspectivas de construção de práticas em seu cotidiano docente.

O objetivo central desse texto é, portanto, apresentar algumas reflexões em torno da formação continuada de professores para o uso de tecnologias digitais, bem como discutir as possibilidades de práticas que envolvam letramentos digitais no contexto escolar, de forma que possam efetivamente contribuir nos processos de ensino e aprendizagem, com base em uma pesquisa realizada com professores em exercício. O foco de nossa discussão se pauta no ensino e aprendizagem de línguas por se tratar de um projeto desenvolvido na área de linguagens, também com a presença de professores de artes e educação física. $\mathrm{O}$ referido estudo foi realizado com professores que atuam no ensino fundamental e médio, em uma escola pública estadual, pautado por uma metodologia de cunho 
intervencionista, construída com base na perspectiva sociointeracionista vygostskiana. O conceito de Zona de Desenvolvimento Proximal representou grande relevância na medida em que foi possível refletir, juntamente com os professores participantes, sobre os processos de uso de tecnologias digitais no contexto de sua ação docente presente, como também àqueles que estavam em estado de formação, ou seja, começando a amadurecer e a se desenvolver com potenciais de ações futuras.

\section{O DESAFIO DA FORMAÇÃO CONTINUADA}

Sem deixar de considerar a complexidade da sala de aula e a natureza histórica e social de alunos e professores envolvidos em um processo de ensino e aprendizagem, precisamos refletir em torno dos letramentos que circulam nesse meio e de como são tratados. Há um conjunto de valores que são manifestados pelos jeitos de ser de cada indivíduo presente no ambiente. Essa manifestação nem sempre é externada, mas, certamente, traduz identidades em construção.

Em nosso entendimento, a complexidade também se apresenta no movimento próprio da formação, no sentido de que todos os envolvidos nesse processo vivenciam de uma maneira ou de outra, níveis diferenciados de formação, não só no que diz respeito às propostas formais oferecidas (na escola e no trabalho), como também àquelas que nos chegam, sobretudo como fruto de nossas interações em meios multimidiáticos que, não sendo oficializadas, não são legitimadas, mas influenciam sobremaneira em nossas atitudes cotidianas, tanto em relação ao que aprendemos e ensinamos, quanto aos mecanismos e estratégias que utilizamos para aprender e ensinar. É fato que a educação não-formal tem crescido de forma surpreendente na rede e em rede, nestes tempos em que novas formas socioculturais se estabelecem, trazendonos novas possibilidades de nos relacionarmos com a educação. Nesse sentido, novos paradigmas emergem das situações vivenciadas pelos indivíduos em decorrência de novos fazeres, em novos lugares e tempos. Segundo Vasconcellos [3], paradigmas são conjuntos de regras e regulamentos que nos estabelecem limites e, por isso, influenciam as nossas percepções, nossas ações. Sendo assim, a forma como vivemos e lemos o mundo à nossa volta reproduz o paradigma ao qual estamos inseridos. Importante, no entanto, salientar que mudança de paradigma requer abertura para novas experiências. Para a autora, "mudanças de paradigmas só podem ocorrer por meio de vivências, de experiências, de evidências que nos coloquem frente a frente com os limites de nosso paradigma atual" [3]. Para vivenciarmos novas experiências é necessário que tenhamos um espírito aberto a novas descobertas e conhecimentos sem, contudo, abandonar as experiências já consolidadas. As novidades podem surgir com base em propostas que sejam agregadoras e não segregadoras.

Em nosso reconhecimento do quanto os avanços tecnológicos ocupam grande espaço na sociedade e de como eles têm alterado de forma significativa não só o nosso cotidiano, como também a realidade social de forma integral, preocupamo-nos com as práticas letradas que circulam no contexto educacional, de forma geral. As práticas letradas são utilizadas, aqui, não para tratar do conhecimento da técnica, mas, sobretudo, para se referir a usos efetivos em práticas sociais e educacionais e que possibilitem a produção de significados. Encontramos pessoas que apresentam habilidade e conhecimento em digitação, mas não conseguem interagir por meio de mensagens instantâneas ou e-mails; apresentam um conteúdo utilizando uma determinada aplicação para apresentação, mas não vislumbram, por exemplo, o compartilhamento de um material didático, em rede, utilizando a mesma interface. Percebemos que novos ambientes virtuais surgem, a todo o momento, dinamizando o ciberespaço e a nossa forma de atuação, demandando novos letramentos e, por isso, a formação é um aspecto determinante no contexto da educação.

Além disso, consideramos de suma importância a nossa atenção a estas mudanças para que possamos analisar de que forma a educação e, especificamente, a escola (como agência formal de letramento) pode contribuir na reorganização desta sociedade [1], apresentando possibilidades de práticas que sejam responsivas à contemporaneidade.

Refletir sobre práticas educacionais responsivas à contemporaneidade é indissociável da reflexão acerca do processo de formação inicial e continuada de professores, pois sem que transformações ocorram na forma de pensar e agir de professores e formadores de professores, as práticas de letramento tradicionais continuarão a ser as únicas legitimadas nas escolas e universidades, contribuindo para aumentar a distância entre as práticas educacionais e a vida e validar processos de marginalização e exclusão sociais [4]

Imbernón [5] pontua que atualmente existe um conjunto de características que devem ser levadas em consideração quando se trata da formação continuada de professores. Segundo o autor, "a formação continuada requer um clima de colaboração entre os professores, sem grandes reticências ou resistências" (p.31). É necessário que haja uma organização estável nos cursos de formação para que exista um apoio e uma aceitação de uma contextualização e de uma diversidade que possa implicar em formas diferentes de pensar e agir. $O$ autor nos esclarece que quando há uma compreensão por parte do professor de que a formação tem um benefício individual e coletivo é que mudanças significativas ocorrem na prática, pois o professor constata melhoria tanto para os estudantes quanto para a atividade docente.

Imbernón [5] ainda afirma que certas formas de trabalho na sala de aula necessitam do apoio de um colega ou de um assessor externo. Nesse sentido, faz-se necessário pensarmos em desenvolver uma cultura colaborativa nas propostas de educação de professores em que seja possível participação, análise e avaliação de forma coletiva, sem, contudo, deixar de considerar os interesses comuns e divergentes na construção de novas possibilidades pedagógicas. Magalhães [6], citando Magalhães e Fidalgo (2005), aponta o papel central da colaboração no processo de coprodução de novos sentidos quanto a teorias, funções e ações que ocorrem quando significados novos e antigos debatem-se por meio de uma avaliação crítica.

Segundo Mello e Dutra [7], a formação continuada de professores tem recebido atenção devido a necessidade de 
atualização de professores de diversas áreas. Pensando na perspectiva de uma pesquisa crítica, em contexto de formação, faz-se necessário enfatizar um modo questionador de pensar e agir que propicie que os participantes organizem a linguagem de forma intencional e reflexiva, de modo que possam analisar criticamente os sentidos de sua ação, oportunizando o desenvolvimento de si e dos outros [6]. Nesse sentido, a formação continuada difere-se em grande medida da formação inicial, pois ela possibilita um refazer da ação docente com base em experiências que podem ser refletidas e revistas no âmbito da própria formação.

Em se tratando de formação continuada e tecnologias digitais, percebemos que muitos professores não relacionam suas atividades sociais e uso de tecnologias digitais a possibilidades relacionadas ao seu fazer pedagógico. $\mathrm{O}$ nosso objetivo, ao desenvolver pesquisas dessa natureza, mobiliza-se no sentido de promover reflexões em torno dos usos pedagógicos que possam ressignificar os processos de ensinar e de aprender.

\section{TECNOLOGIAS DIGITAIS E NOVOS LETRAMENTOS}

Precisamos, hoje, nos perguntar de que forma a instituição escola lida com a novidade da tecnologia digital. Entendemos que nesse espaço a atuação do professor é essencial, pois é ele o responsável em articular conteúdo, tecnologias (novas e velhas) e práticas pedagógicas para que o aluno possa efetivamente construir conhecimentos por meio de suas próprias experiências. Lemke [8] nos lembra que "com tanto para ser aprendido precisamos pensar um pouco em como as novas tecnologias da informação podem transformar nossos hábitos institucionais de ensinar e aprender". Ao unirmos hábitos de ensinar e aprender com formação continuada de professores nos reportamos a Paulo Freire quando nos esclarece sobre a dimensão do processo dialógico, afirmando que "através do diálogo, refletindo juntos sobre o que fazemos e não sabemos, podemos, a seguir, atuar criticamente para transformar a realidade" [9] e, em consequência, o nosso fazer, com base na percepção de que como seres históricos e culturais, estamos em constante processo de aprendizagem. Soares [1], em consonância com esses ideais, aponta:

\footnotetext{
Por estarmos sempre em interação com o mundo, este processo se caracteriza como dinâmico e dialético. E isso demonstra que, se estamos em constante interação e se, a partir da interação entre sujeito e objeto, o conhecimento é construído, temos então o fundamento de que somos seres inacabados. Estamos em processo de aprendizagem constante, e a nossa experiência como seres humanos nos ensina a cada dia novos caminhos.
}

Os novos caminhos podem nos levar a construir novas práticas e novos significados. Em se tratando dos significados que podem emergir dos usos de tecnologias digitais, Gee [10] assevera que eles são determinados por práticas sociais, culturais, históricas e institucionais de diferentes grupos, envolvendo muito mais do que apenas o uso. O autor apresenta mudanças significativas geradas, em decorrência dos avanços tecnológicos, que podem ter um impacto direto nas ações docentes: a) Hoje, tornou- se acessível a produção de mídia, fazendo com que as relações entre consumo e produção sejam redimensionadas. E, como citamos anteriormente, a Web 2.0 nos permite essa mudança de lugar e, consequentemente, uma reconfiguração no conceito de autoria, na medida em que as tecnologias se tornam mais sofisticadas, com abertura para meios mais viáveis de conexão e interconexão no e com o mundo. Em termos educacionais os Recursos Educacionais Abertos REA, por exemplo, tem possibilitado que, por meio de licenças livres e abertas, a criação, a mixagem, a colaboração e o compartilhamento de materiais didáticos se expandam largamente.

b) A relação entre participante e expectador passa a ser repensada. Se agora a produção é possível há, também, uma mudança no que diz respeito às possibilidades de participar da rede de forma ativa e não apenas como um expectador passivo. Muitas práticas que até pouco tempo eram reservadas apenas a profissionais da área de computação são, hoje, vivenciadas por pessoas sem vínculos profissionais nessa área.

c) A organização de redes de relacionamento que se estruturam com base em objetivos bem específicos. Nesse caso, podemos citar o crescimento de iniciativas de cursos livres de língua estrangeira oferecidos no Youtube. Percebemos que, nesse contexto, existem objetivos específicos delimitados por quem ensina, como também por quem aprende.

d) A emergência de "Pro-Ams" em referência aos jovens que se utilizam dos dispositivos digitais fora da escola para aprender e se tornarem experts em muitos e diferentes domínios.

Com base nesse entendimento, alimentamos o desejo de estarmos atentos aos letramentos [11] digitais no processo de ensino e aprendizagem de línguas, visto que os usos, principalmente no que diz respeito aos alunos acontecem, muitas vezes, de forma acrítica e, nesse sentido, precisamos de uma compreensão mais ampla sobre as práticas sociais, culturais e históricas em que estão envolvidos. No que se refere aos professores, percebemos que práticas de letramento na esfera digital ocorrem no campo social, mas não no profissional e pedagógico.

Segundo Soares e Barreto [12], letramento digital implica na realização de práticas sociais e culturais diferentes daquelas utilizadas sem suportes computacionais. A presença do digital é inerente a esses letramentos sem deixar de levar em consideração que sua manifestação pode ser combinada com práticas não digitais, ou seja, há uma convergência entre letramentos antigos e novos. São eventos que possibilitam a construção de significados em virtude de práticas sociais e culturais situadas. Nesse sentido, podemos afirmar que o conceito de letramento digital não se limita às tecnologias em si e não trata apenas de habilidades em manuseio, mas, essencialmente, nos significados que emergem das práticas sociais e culturais de grupos específicos. Rojo [13] nos chama a atenção para as formas como as tecnologias digitais podem favorecer no ensino de línguas: 
Para o ensino de língua portuguesa nas escolas, de saída, podemos vislumbrar novas e interessantes possibilidades - em relação aos LD impressos - de trabalhar com textos e gêneros que eram abordados com dificuldades, como os gêneros orais e os multimodais e hipermidiáticos [...] Nos dois casos (português e língua estrangeira), no entanto, a presença das TICs e de dispositivos digitais conectados em sala de aula tem efeitos de alcance mais amplo, como por exemplo, poder acessar outras amostras e acervos que não somente aqueles valorizados e selecionados por autores e editores de impressos[...] [13].

Não podemos deixar de levar em consideração o potencial das interfaces disponíveis na Web 2.0, como possibilidade de (re)criação, colaboração e interação em que o professor pode, com base em seu conteúdo, construir diversificado material de ensino e de aprendizagem, proporcionando, inclusive, possibilidades didáticas online e multimidiáticas. Os letramentos, então, podem interconectar-se com as novas possibilidades que nos chegam com grande velocidade e facilidade e que nos tornam menos capazes de prever as transformações futuras. Sobre isso Lemke [8] pontua:

\begin{abstract}
Ninguém pode prever as transformações do século XXI durante a revolução tecnológica da informação. Nós certamente não podemos continuar ensinando nossos estudantes apenas os letramentos da metade do século $\mathrm{XX}$, ou simplesmente colocar na frente deles os letramentos mais avançados e diversos de hoje. Precisamos ajudar essa geração a aprender a usar sabiamente os letramentos e esperar que eles saiam-se melhor do que nós.
\end{abstract}

Chamamos a atenção para a necessidade de tratarmos desses letramentos de forma crítica e reflexiva para que seu uso não se configure apenas como um recurso tecnológico a mais, na sala de aula. É importante que os usos estejam atrelados a objetivos bem definidos $\mathrm{e}$ articulados com o conteúdo proposto e a metodologia planejada, sem deixar de levar em consideração as práticas sociais e culturais vivenciadas pelos alunos. Nesta perspectiva, consideramos que o ciberespaço pode representar um diferencial nas práticas desenvolvidas pelos professores dentro e fora da escola, na medida em que ele é compreendido com base na infraestrutura material da comunicação digital, nas informações que essa estrutura abriga e nos indivíduos que navegam, interagem e transformam esse meio.

Considerado por Lévy [2] como o suporte da inteligência coletiva, o ciberespaço tem como características: ubiquidade da informação, documentos interativos interconectados, telecomunicação recíproca e assíncrona em grupo ou entre grupos. Todas essas carcterísticas virtualizantes e desterritorializantes fazem dele o vetor de um universo aberto. Nesses termos, temos um campo fértil para o desenvolvimento de práticas educacionais marcadas pelo uso de tecnologias digitais em contextos de realidades síncronas e assíncronas mediadas por computadores, dispositivos portáteis e telefonia móvel.

\section{O CONTEXTO DA PESQUISA}

Com o objetivo de investigar de que forma os letramentos digitais podem contribuir nos processos de ensino e aprendizagem de línguas, esta pesquisa vinculase aos estudos desenvolvidos pela Linguística Aplicada Crítica (LAC) ([14]; [15]; [16] [17]; [18]; [19]; [20]) pautada na perspectiva de uma proposta que seja responsiva à vida social.

Já não se usa mais "aplicar" uma teoria a um dado contexto para testá-la. Também não se trata mais de explicar e descrever conceitos ou processos presentes em determinados contextos, sobretudo escolares, à luz de determinadas teorias emprestadas, como foi feito com os processos (processamentos) em leitura e produção de textos, ou com a interação em sala de aula enquanto (tipo de) conversação, ou com a interlíngua enquanto processo de projeção da LM sobre a língua estrangeira. A questão é: não se trata de qualquer problema - definido teoricamente -, mas de problemas com relevância social suficiente para exigirem respostas teóricas que tragam ganhos a práticas sociais e a seus participantes, no sentido de uma melhor qualidade de vida, num sentido ecológico [15].

Rajagopalan [17], em consonância com esse pensamento, explica que quando ele se refere a uma linguística aplicada crítica seu objetivo se move em direção a questões práticas. Em suas palavras "não é a simples aplicação da teoria para fins práticos, mas pensar a própria teoria de forma diferente, nunca perdendo de vista o fato de que o nosso trabalho tem que ter alguma relevância. Relevância para as nossas vidas, para a sociedade de modo geral" (p, 12).

Nesse sentido, essa investigação insere-se nesses estudos por propor uma metodologia de trabalho que considera o movimento dos eventos e práticas de letramento ([11]; [21]; [22]; [23]) digital no trato com as línguas, em sala de aula, bem como a organização da linguagem de forma reflexiva e intencional, em momentos de formação, oferecendo possibilidade para que a análise das ações pedagógicas ocorra de forma significativa e propicie as transformações necessárias e possíveis.

Não se trata de simplesmente compreender e descrever as novas formas de comunicação e os novos discursos e gêneros emergentes em contextos virtuais, mas de fazêlo para refletir sobre as novas possibilidades de melhoria da qualidade de vida das pessoas, a partir destes novos instrumentos [...] [13].

Há, nesse sentido, um entendimento de que o indivíduo emerge pelos processos de interação social como alguém que é (re)constituído por meio das várias práticas discursivas das quais participa e não como produto final [24]. No contexto dessa pesquisa, não há preocupação com resolução de problemas, mas de problematizar as questões construídas para que possíveis alternativas possam ser pensadas e contextualizadas. É uma tentativa de refletir sobre a prática investigativa em movimento.

A pesquisa foi desenvolvida em parceria com uma escola pública estadual localizada no município de Vitória da Conquista, na Bahia, com 06 professores que atuam nas disciplinas língua portuguesa, língua inglesa, educação física e artes. $\mathrm{O}$ projeto inicial previa a participação dos professores de línguas, mas como os encontros aconteciam 
nos horários de Atividades Complementares (AC) dos professores da área de Linguagens houve uma solicitação por parte dos professores de artes e educação física, inseridos na mesma área, para que eles também integrassem no grupo de participantes da pesquisa. Os encontros presenciais eram semanais e tinham uma duração aproximada de 3 horas.

O primeiro procedimento realizado com o grupo foi um mapeamento das atividades desenvolvidas pelos professores, no que diz respeito às práticas de leitura e escrita em sala de aula, com vistas a verificar se existiam práticas digitais. Após o mapeamento, apresentamos o ambiente Moodle aos professores, seguida por uma ambientação, para que o referido espaço virtual fosse utilizado pelos participantes da pesquisa durante todo o processo da investigação. Nesse sentido, além dos encontros presenciais que aconteciam nos horários de atividades complementares dos professores, o ambiente virtual foi utilizado como forma de interação.

A pesquisa foi organizada com base nos seguintes princípios:

a) estudos teóricos para aprofundamento das concepções de ensino e aprendizagem de línguas, bem como dos conceitos pertinentes ao uso de tecnologias digitais na educação, com foco nas práticas de letramento digital no processo de ensino e aprendizagem de línguas;

b) Oficinas pedagógicas com o uso de tecnologias digitais, com foco nas práticas de leitura e escrita;

c) Oficina de planejamento de atividades com o uso das tecnologias digitais estudadas durante as oficinas;

c) desenvolvimento das práticas planejadas, durante o período das oficinas, em sala de aula;

d) reflexão das práticas desenvolvidas junto ao grupo participante da pesquisa.

A seguir, elencamos algumas considerações sobre as atividades desenvolvidas junto aos professores, na execução das atividades da pesquisa.

\section{ALGUMAS CONSIDERAÇÕES EM TORNO DOS LETRAMENTOS DIGITAIS: A PESQUISA REALIZADA}

O mapeamento realizado com os professores participantes da pesquisa demonstrou que a utilização de tecnologias mais novas em sala de aula não fazia parte de seu cotidiano, apesar de alguns afirmarem que já haviam participado de cursos que envolviam a temática 'Tecnologias digitais e educação'. Este fato nos remete à Imbernón [5] quando afirma que o caráter transmissor da formação com a supremacia de uma teoria descontextualizada, distante dos problemas práticos dos professores, pouco inova. Naquele momento, ficou evidenciado que teoria e prática caminhavam sem um diálogo produtivo. Consideramos, então, que adentrar o espaço dos professores, em seu local de trabalho, favoreceria a construção de propostas didáticas mais aproximadas da realidade de cada um. Nossos encontros eram realizados semanalmente no horário de $\mathrm{AC}$ dos professores como forma de participar de seu cotidiano e em seu exercício profissional. Julgamos que essa proposta representa um diferencial na concepção de formação, na medida em que as práticas formativas misturam-se com o cotidiano do professor dentro do espaço escolar, ou seja, significam parte de seu trabalho na escola.

Outra questão que nos chama a atenção é a possibilidade de estarem juntos, dividindo suas dúvidas e dificuldades tanto nos momentos de interação com as interfaces digitais, como nos momentos de planejamento de atividades com seus alunos. A instauração de uma nova cultura formadora gera novos processos na teoria e na prática. Ademais, o clima de colaboração entre os professores favorece a reflexão individual e coletiva sobre seus fazeres em sala de aula. Há, nesses termos, um interesse em tratar de atividades que potencializem a Zona de Desenvolvimento Proximal (ZPD) vygostskiana. Sobre isso Soares [1], pautada em Vygotsky (1998) pontua:

A Zona de Desenvolvimento Proximal se caracteriza, portanto, como o caminho que o indivíduo vai percorrer para desenvolver funções que estão em processo de amadurecimento e que se tornarão funções consolidadas, estabelecidas no seu nível de desenvolvimento real. Esta zona se caracteriza como sendo um domínio psicológico em constante transformação, explicado pelo fato de o ser humano estar em constante aprendizado e, por isso, em constante mudança. Essa possibilidade de alteração no desempenho de uma pessoa pela interferência de outra é fundamental na teoria de Vygotsky. É de extrema importância a interação social no processo de construção das funções psicológicas humanas [1]

Em se tratando das oficinas, houve uma diferença significativa em relação àquelas apresentadas no momento da escrita do projeto e as realizadas com os professores no decorrer de sua execução. Esse fato tem estreita relação com a forma como a Internet tem modificado nossos hábitos de aprender, ensinar e de viver em uma sociedade marcada pelos avanços tecnológicos. No projeto inicial havia previsão para oficina de áudio, oficina de vídeo, oficina de blog e práticas pedagógicas em redes sociais. No entanto, as tecnologias têm avançado de forma surpreendente e têm nos apresentado ambientes interativos, baseadas em uso de licenças livres que podem ser compartilhadas em rede. Nesse sentido, em discussão com o grupo de professores participantes do projeto, resolvemos fazer uma modificação na ordem das oficinas com inclusão de novas interfaces: Delicious ${ }^{1}$, Quizlet ${ }^{2}$, Prezi $^{3}, H Q^{4}$ e o Celtix ${ }^{5}$. Como o site de rede social Facebook nos proporciona a construção de páginas de forma bastante produtiva decidimos por não fazer a oficina de blog e utilizar o Facebook como forma de dinamizar a leitura e a escrita. Sobre isso, Imbernón [5], ao apresentar propostas em torno da formação continuada de professores, propõe "partir dos projetos das escolas, com o objetivo de os professores decidirem a formação de que necessitam para avançar na elaboração, no desenvolvimento e na avaliação do projeto" [5] .

Com exceção do Facebook, que era utilizado pelos professores em interações sociais, todas as outras tecnologias digitais apresentadas ainda não eram

\footnotetext{
${ }^{1}$ Serviço de 'Social bookmarks'.

${ }^{2}$ Plataforma de estudos baseada em cartões.

${ }^{3}$ Programa para construção de apresentações dinâmicas.

${ }^{4}$ Software para construção de quadrinhos.

${ }^{5}$ Programa usado para roteirização de vídeos.
} 
conhecidas por eles. A possibilidade de criação, recriação, colaboração e interação em ambientes como Quizlet e Prezi, potencializou reflexões relevantes sobre o propósito em usar tecnologias (velhas e novas) em sala de aula e em que medida elas podem fazer diferença na forma como o aluno aprende. Esse fato nos leva a refletir sobre a necessidade em articular conteúdo, tecnologia e pedagogia de forma que possam contribuir, efetivamente, no aprendizado dos alunos. A integração de tecnologias no ensino não é tarefa fácil [25], mas necessária e requer conhecimentos que vão muito além das habilidades de manipulação e técnica. Todos os professores envolvidos no projeto tiveram a oportunidade de utilizar os ambientes virtuais trabalhados nas oficinas em seu planejamento e demonstraram satisfação em torno da possibilidade de criação e autoria em sua prática pedagógica. No decorrer das atividades todos os professores mantinham um diário de vivências no Moodle como forma de refletir sobre suas ações. Alguns relatos são expressivos:

Preparei meu primeiro material sobre Plural of Nouns e servirá de revisão do conteúdo. Estou bastante animada e começando a derrubar os primeiros tijolinhos da grande barreira erguida entre mim e as tecnologias.

Hoje participarei de uma oficina para a construção de H.Q. Tenho certeza que será mais uma experiência maravilhosa.

Então fiquei muito alegre porque pude dar minha aulas com o prezi para as turmas da tarde.

Estou visualizando que minhas aulas estão conseguindo uma atenção maior de meus alunos, pois os recursos utilizados por mim vêm mudando com o aprendizado do curso de letramento.

A oportunidade de ser autor de seus materiais de aula representa uma possibilidade de construção de significados por parte do professor que redireciona seu fazer pedagógico e sua autonomia. Os excertos acima nos demostram o contentamento dos professores em produzir seu próprio material e disponibilizá-los aos alunos. Essas produções foram realizadas em dois momentos: nos encontros agendados na escola e individualmente em momentos fora da escola. Durante os encontros, o trabalho colaborativo demonstrou a importância da intervenção na ZPD dos participantes como forma de potencializar novas aprendizagens. A partir do conhecimento e das necessidades apresentadas pelos professores, foi possível o planejamento de situações de intervenção condizentes com sua realidade e de seus alunos. Durante os encontros, eles eram sempre incentivados a disponibilizarem seu material em rede para que os alunos pudessem acessar fora do espaço escolar como forma de possibilitar a ubiquidade da informação.

Em relação à rede social Facebook, apesar de ser reconhecida e muito utilizada pelos professores em suas relações sociais, eles ainda não vislumbravam um uso no campo educacional. Muito frequentemente os usos são efetivos, mas não há uma proposição de ações educativas. Amante [26] ressalta que as pesquisas de Pempek et al, (2009), Selwyn (2007), Madge et al (2009) e Ophus e Abbitt (2009) "têm revelado que as interacções com propósitos de aprendizagem, ou ligadas a usos educativos formais e ao contato com a Escola são muito restritas". A proposta em ter páginas temáticas em rede traz uma possibilidade de ampliação das relações vivenciadas em sala de aula, não só em termos de conteúdos trabalhados, mas sobretudo no que diz respeito ao desenvolvimento de habilidades que são propiciadas pelas interações virtuais e que não são possíveis em outros meios. Umas das questões que é levada em consideração, nesse contexto, diz respeito à relação entre consumo e produção:

Agora, o enfoque não pode ser mais restritivo ao consumo. As pessoas consomem, mas também gostam e querem produzir, opinar, relatar suas experiências, falar de si, compartilhar. O consumo deixa de ser a única maneira como se podia usar a mídia. Agora se fala em consumo ativo, interativo, participativo. Quando as oportunidades são dadas, as pessoas querem fazer e falar sobre o que fazem, pois sempre tem muito a dizer [27].

Em se tratando das interações no Moodle, percebemos um estranhamento dos professores em relação a certas atividades no ambiente como, por exemplo, as discussões teóricas em fóruns de discussão. Tais discussões requerem um tempo extra, tanto para leituras como para o desenvolvimento da discussão de forma online (em qualquer tempo e lugar). Com uma carga horária de 40 ou 60 horas, os professores não dispunham do tempo necessário para uma participação mais intensiva no contexto dessa interface, apesar de o fórum de discussão se constituir como um gênero que pode possibilitar processos de interação e de construção coletiva de significados por parte dos que ali interagem [28]. Ainda que, no nosso entendimento, essa forma de interação caracteriza-se como um aspecto relevante nos processos de letramento digital, pois além de apresentar o ambiente virtual como uma possibilidade pedagógica para $o$ professor ele também favorece processos de construção coletiva de ideias, decidimos por priorizar as discussões teóricas nos encontros presenciais, por compreendermos a importância dessa atividade de discussão no desenvolvimento da pesquisa. Percebe-se, contudo, que a formação continuada, nesse contexto, torna-se essencial na medida em que o processo de formação inicial não tem contemplado esses letramentos.

Uma das interfaces bastante utilizadas pelos professores no Moodle e que merece nossa atenção referese ao Portfólio. Em forma de um fórum, uma pasta portfólio foi criada por cada professor, para compartilhamento de suas produções didáticas, que eram postadas e comentadas por todos os participantes. Fato que nos remete ao ciberespaço como suporte da inteligência coletiva [2], e que apresenta características como ubiquidade da informação e utilização de documentos interativos interconectados. $\mathrm{O}$ uso do Portfólio serviu não apenas para compartilhamento mas, principalmente, como meio de reflexão e avaliação no momento em que possibilitou que os participantes refletissem sobre o trabalho do outro e sobre si numa relação de cooperação e construção de possibilidades. Ademais, é uma forma de estimular a autonomia dos professores. Sobre isso, Soares e Barreto [12] salientam que o reconhecimento da natureza social e coletiva dos processos autônomos, vivenciados em ambientes virtuais de aprendizagem, não minimiza a importância da individualidade de cada sujeito envolvido no processo. 
No que se refere às oficinas pedagógicas e planejamento de atividades, salientamos que houve um envolvimento intenso dos professores com as interfaces apresentadas. Além dos encontros presenciais e do Moodle para compartilhamento de todas as produções dos professores também utilizamos um grupo no aplicativo WhatsApp, de forma bastante produtiva. Importante salientar que durante o desenvolvimento das atividades didáticas havia um indicativo, por parte dos professores, em construir parcerias. Além de compartilharem entre si as atividades construídas também combinavam em auxiliar o colega no laboratório de informática nos momentos em que desenvolviam atividades com os alunos. Ação que no remete aos estudos de Magalhães [6], no que diz respeito à colaboração, como também à Imbernón [5] quando afirma que certas formas de trabalho na sala de aula necessitam do apoio de um colega ou de um assessor externo. Segundo os professores, a dispersão é mais favorável e a ajuda do colega torna-se importante na organização do ambiente.

\section{CONSIDERAÇÕES FINAIS}

As práticas de letramento digital no contexto educacional favorecem atividades didáticas interativas e dinâmicas no momento em que podem ser construídas, de forma colaborativa, pelos professores, sem deixar de levar em consideração que a ação individual de cada um seja essencial na construção do coletivo. Chamamos a atenção para $o$ fato de que algumas das interfaces utilizadas durante o projeto, podem ser (re)significadas pelos professores em propostas pessoais de desenvolvimento. $\mathrm{O}$ site de Social Bookmark utilizado, por exemplo, pode ter um sentido pessoal para o professor na organização de suas páginas favoritas, sem necessariamente, compartilhar com outras pessoas. Nesse sentido, é relevante que as práticas sejam norteadas por objetivos definidos.

É importante salientar que as tecnologias sempre fizeram parte do fazer pedagógico e que o uso de novas tecnologias deve ser determinado pela necessidade de articulação entre conteúdo, tecnologia e pedagogia, com vistas a processos construtivos de aprendizagem e não apenas como recurso didático.

Consideramos relevante a participação de professores em práticas que envolvam letramentos digitais, em contextos de formação, pois apesar de vivermos em uma sociedade em que as tecnologias se tornam cada vez mais presentes o seu uso, na dimensão pedagógica, ainda se configura como novidade, na vida escolar. Essa novidade requer um olhar diferenciado no que diz respeito às políticas públicas educacionais para formação inicial e continuada dos professores.

A formação continuada representa um diferencial no momento em que possibilita ao professor a construção de práticas que condizem com a sua realidade e com as suas possibilidades reais de desenvolvimento. No desenvolvimento do projeto, inúmeras oportunidades de práticas de letramento digital foram apresentadas, mas ressaltamos o fato de que cada professor participante expressou uma maneira singular em torno dos usos das interfaces trabalhadas no projeto. Nesse sentido, é importante salientar que o ser histórico e cultural revela-se em sua prática e direciona suas experiências com base em sua realidade e em sua forma de conceber o mundo.

\section{REFERÊNCIAS}

[1] SOARES, C. V. C. O, Intervenção pedagógica do professor em ambientes informatizados de aprendizagem. Vitória da Conquista: Editora UESB, 2010.

[2] LÉVY, P, Cibercultura. São Paulo: Ed. 34, 1999.

[3] VACONCEllos, M. J. E, Pensamento sistêmico: o novo paradigma da ciência. Campinas: Papirus, 2002.

[4] OliveIRA, M. B. F de; SZUNDY, P.T.C, Práticas de multiletramentos na escola: por uma educação responsiva à contemporaneidade. Revista Bakhtiniana, São Paulo, 9 (2): 184205, Ago./Dez. 2014.

[5] IMBERNÓN, F, Formação continuada de professores. Lisboa: Porto Alegre: Artmed, 2010

[6] MAGAlhÃES, M.C.C, Pesquisa crítica de colaboração: escolhas epistemo-metodológicas na organização e condução de pesquisas de intervenção no contexto escolar In: MAGALHÃES, M.C.C.; FIDALGO, S. S. (Orgs).Questões de método e de linguagem na formação docente. Campinas, SP: Mercado de Letras, 2011.

[7] MELLO, H; DUTRA, D. P. A colaboração crítica na formação contínua de professores. In: MAGALHÃES, M.C.C.; FIDALGO, S. S. (Orgs). Questões de método e de linguagem na formação docente. Campinas, SP: Mercado de Letras, 2011.

[8] LEMKE, J. L. Letramento metamidiático: transformando significados e mídias. Tradução de Clara Dornelles. Trab. Linguística. Aplicada. [online]. v. 49, n. 2, p. 455-479, jul./dez. 2010.

[9] FREIRE, P; SHOR, I. Medo e Ousadia - o cotidiano do professor. Rio de Janeiro: Paz e Terra, 1987

[10] GEE J. P. A situated-sociocultural approach to literacy and technology. In: Baker E. (Ed.) The new literacies: Multiple perspectives on research and practice (pp. 165-193). New York: Guilford, 2010

[11] STREET, B. Eventos de letramento e práticas de letramento: teoria e prática nos novos estudos do letramento. In: MAGALHÃES, Izabel. (Org.). Discurso e Práticas de Letramento: Pesquisa Etnográfica e formação de professores. Campinas, SP: Mercado das Letras, 2012.

[12] SOARES. C. V. C.de O; BARRETO. A. B. Reflexões em torno da autonomia docente/discente em práticas de leitura e escrita em ambientes virtuais de aprendizagem. Interletras, v. 6, Edição número 24, outubro de 2016 - Abril de 2017.

[13] ROJO, R. Materiais didáticos no ensino de línguas.In: MOITA LOPES, Luiz Paulo da. (Org.) Linguística Aplicada na Modernidade Recente: Festschrift para Antonieta Celani. São Paulo: Parábola, 2013.

[14] SIGNORINI, I. A questão da língua legitima na sociedade democrática: um desafio para a linguística aplicada contemporânea. In: MOITA LOPES, L. P. (Org.). Por uma Linguística Aplicada Indisciplinar. São Paulo: Parábola Editorial, 2006. 279 p.

[15] Rojo, R. Fazer Linguística Aplicada em perspectiva sócio-histórica: privação sofrida e leveza de pensamento. In: MOITA-LOPES, L. P. (Org.) Por uma Linguística Aplicada indisciplinar. São Paulo: Parábola, 2006, p. 252-275.

[16] RAJAGOPALAN, K. Repensar o papel da linguística aplicada. In: MOITA LOPES, L. P. (Org.). Por uma Linguística Aplicada Indisciplinar. São Paulo: Parábola Editorial, 2006. p. 279

[17] RAJAGOPALAN, K. Por uma linguística crítica: linguagem, identidade e a questão ética. 3. ed. São Paulo: Parábola, 2008

[18] PENNYCOOK, A. Uma linguística aplicada transgressiva. In: MOITA LOPES, L. P. (Org.). Por uma Linguística Aplicada Indisciplinar. São Paulo: Parábola Editorial, 2006. 279 p.

[19] MOITA LOPES, L. P. (Org.). Por uma Linguística Aplicada Indisciplinar. São Paulo: Parábola Editorial, 2006.

[20] CAVALCANTI, M. C. (Org.) Linguística Aplicada - suas faces e interfaces. Campinas, São Paulo: Mercado de Letras, 2007.

[21] STREET, B.. Letramentos Sociais: abordagens críticas do letramento no desenvolvimento, na etnografia e na educação. Tradução Marcos Bagno, São Paulo: Parábola Editorial. 2014 
[22] BARTON, D. Literacy: an introduction to the Ecology of written language. Cambridge: Blackwell, 1994

[23] BARTON, D; HAMILTON, M; IVANIC, R. Situated literacies. London: Routledge, 2000.

[24] CAVALCANTI, M.C. Um olhar metateórico e metametodológico em Lingüística Aplicada:implicações éticas e políticas. In L.P. da Moita Lopes (org)Por uma Lingüística Aplicada INdisciplinar.São Paulo.Parábola Editorial.2006.

[25] KOEHLER, M. J.; MISHRA, P. Introducing Technological Pedagogical Content Knowledge. Annual Meeting of the American Educational Research Association New York City, March 24-28, 2008

[26] AMANTE, L. Facebook e novas sociabilidades: contributos da investigação. N: PORTO, C.; SANTOS, E. (org). Facebook e Educação: Publicar, curtir, compartilhar. Campina Grande, PB: EDUEPB, pp. 85-112, 2014.

[27] COUTO. E. S. Pedagogias das conexões: compartilhar conhecimentos e construir subjetividades nas redes sociais digitais. In: PORTO, C.; SANTOS, E. (org). Facebook e Educação: Publicar, curtir, compartilhar. Campina Grande, PB: EDUEPB, pp. 85-112, 2014.

[28] SOARES, C. V. C. O. O processo interativo no fórum de discussão on-line. Fólio -Revista de Letras Vitória da Conquista v. 4, n. 2 p. 91-109 jul./dez. 2012 